\title{
Conundrum in Management of a Large Periapical Cyst: A Dental Anchor?
}

\author{
Deval Arora ${ }^{1}$, Tarang C Arora ${ }^{2}$, Abhay M Tripathi ${ }^{3}$, Sonali Saha ${ }^{4}$, Kavita Dhinsa ${ }^{5}$
}

\begin{abstract}
Inflammatory cysts of jaw found at apices of teeth with diseased and necrotic pulp are known as radicular cysts. These cysts originate from proliferating cell rests of Malassez subsequent to necrosis of pulp in a nonvital tooth. Such a condition is commonly asymptomatic but may develop in gradual growth in the altered region. Radiographically, the lesion may be observed as a round or oval well-circumscribed radiolucent expanse including the apex of the affected tooth. Certain authors recommend that radicular cysts must be surgically enucleated to eliminate all remnants of the epithelium. However, surgical enucleation of an extensive cystic lesion can cause damage to other adjoining teeth or anatomic structures. Thus, remedy should be initiated by more conservative procedures of decompression, to curtail the size of the lesion. This case report focuses on fruitful surgical management of a large infected radicular cyst treated only by marsupialization.

Keywords: Inflammatory cysts of jaw, Marsupialization, Radicular cyst.

Journal of South Asian Association of Pediatric Dentistry (2019): 10.5005/jp-journals-10077-3028
\end{abstract}

\section{INTRODUCTION}

Radicular cyst is among the most common odontogenic cystic lesions of inflammatory origin, arising from epithelial remainder of periodontal ligament. ${ }^{1}$ It constitutes approximately $52-68 \%$ of cysts affecting human jaw. ${ }^{2}$ The lesion is not clinically detectable when small and is oftentimes detected as coincidental finding on a radiographic inspection. ${ }^{1}$

It is commonly seen at the apex of the associated tooth, but sometimes can be observed on lateral facet of the roots related to lateral accessory root canals as well. These cysts are a direct aftermath of chronic apical periodontitis, but every chronic lesion does not evolve into a cyst. Radicular cysts may ensue in the periapical area of any tooth, and at any age, but are scarcely noticed with primary dentition. It is also frequently seen around maxillary teeth.

Patient complains also of gradually increscent swellings. The cyst may displace contiguous teeth or result in mild root resorption. Radicular cyst may be treated by prevalent nonsurgical root canal therapy when the lesion is limited or surgical modalities like enucleation, marsupialization, or decompression when the lesion is considerable. ${ }^{3}$ The preferred treatment depends on the extent and localization of the lesion, the bone density of the cystic wall, and its contiguity to critical structures. Nonetheless, despite the preference, the treatment option should be kept as conservative as achievable. ${ }^{4}$

The goal of this article is to highlight a case of effective surgical management of an infected radicular cyst by marsupialization in a young primary lower second molar.

\section{Case Description}

A 9-year-old boy came with a primary complaint of pain and swelling in the right lower back tooth region of the jaw. Extraoral examination revealed a diffuse enlargement affecting the lower right side of the face (Fig. 1). Intraoral examination revealed diffuse distention extending from 84 to 46 , measuring $4 \times 2 \mathrm{~cm}$. Swelling was hard and nonfluctuant. The involved teeth were found to be firm, and no surface discharge was present.
${ }^{1}$ Department of Pedodontics and Preventive Dentistry, Autonomous State Medical College, Shahjahanpur, Uttar Pradesh, India

${ }^{2-5}$ Department of Pedodontics and Preventive Dentistry, Sardar Patel Post Graduate Institute of Dental and Medical Sciences, Lucknow, Uttar Pradesh, India

Corresponding Author: Deval Arora, Department of Pedodontics and Preventive Dentistry, Autonomous State Medical College, Shahjahanpur, Uttar Pradesh, India, Phone: +91 9415315427, e-mail: devalarora@gmail.com

How to cite this article: Arora D, Arora TC, Tripathi AM, et al. Conundrum in Management of a Large Periapical Cyst: A Dental Anchor? J South Asian Assoc Pediatr Dent 2019;2(2):61-63.

Source of support: Nil

Conflict of interest: None

Furthermore, a grossly decayed mandibular right deciduous second molar (85) was also observed with swelling. An orthopantomogram (OPG) was taken which divulged a welldescribed unilocular radiolucency in relation to the right mandible

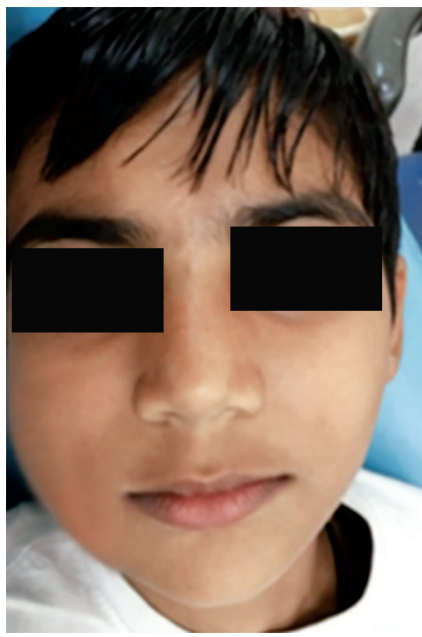

Fig. 1: Preoperative clinical photograph

(O) The Author(s). 2019 Open Access This article is distributed under the terms of the Creative Commons Attribution 4.0 International License (https://creativecommons. org/licenses/by-nc/4.0/), which permits unrestricted use, distribution, and non-commercial reproduction in any medium, provided you give appropriate credit to the original author(s) and the source, provide a link to the Creative Commons license, and indicate if changes were made. The Creative Commons Public Domain Dedication waiver (http://creativecommons.org/publicdomain/zero/1.0/) applies to the data made available in this article, unless otherwise stated. 


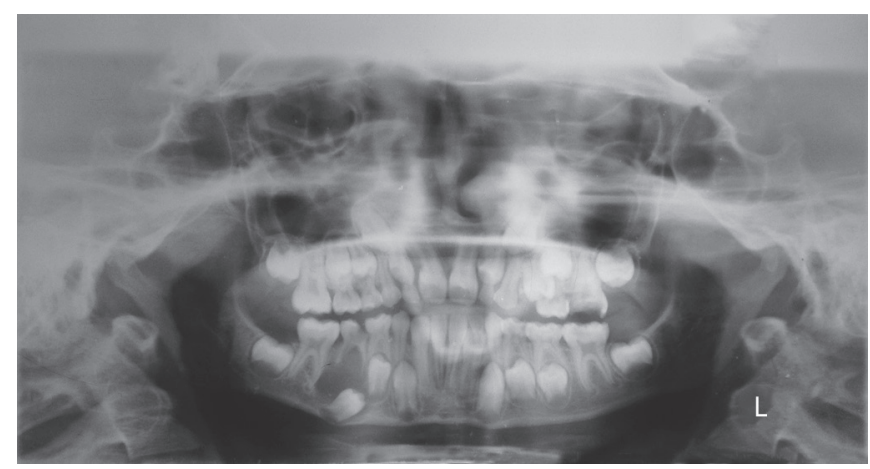

Fig. 2: Preoperative orthopantomogram revealing radiolucency in relation to 84 regions to 46 regions

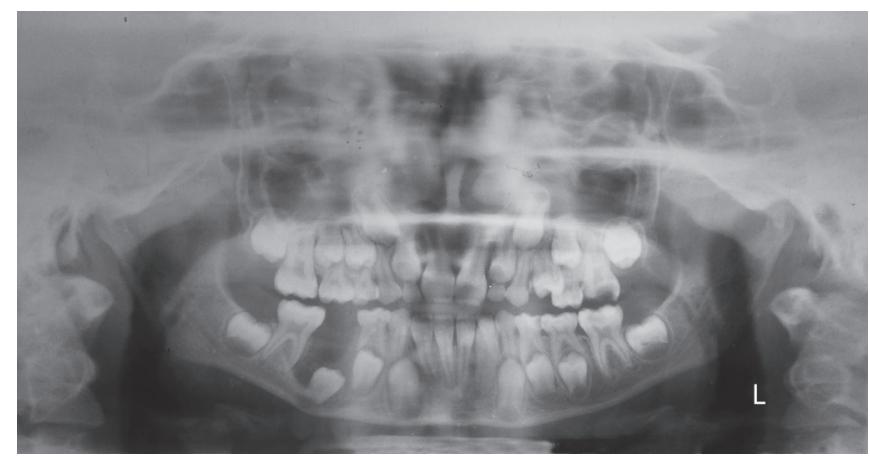

Fig. 4: Orthopantomogram after 3 months revealed decreased radiolucency of cystic space and evidence of new bone formation

from the 84 region to 46 region closely associated with the grossly destructed 85 (Fig. 2). Provisional diagnosis of a radicular cyst was made. An informed consent was taken from the patient preceding the initiation of procedure.

Grossly carious 85 was extracted followed by surgical management (marsupialization) of the radicular cyst to prevent extraction of the erupting mandibular right permanent second premolar (45) which otherwise would have to be done in case of enucleation. The erupting 45 showed mesioangular impaction. Complete blood count and other routine investigations were within acceptable limits.

The procedure was surgically carried out under local anesthesia. The grossly carious tooth (85) was elevated and extracted. Hemorrhage was controlled. Vertical incisions were made to release the flap and to expose the underlying defect for proper curettage of granulation tissue from the cystic cavity over the alveolar crest region after extraction of 85 . The underlying cyst lining was gently eased away from the cavity and specimen sent for histopathological examination (Fig. 3). A cystic cavity was irrigated with the normal saline and povido-iodine solution. The cavity was then packed with half inch width ribbon gauze impregnated with iodoform glycerin paste. Postoperative directions were given to the patient, who was kept under antibiotics and analgesics coverage for infection and pain control. Dressing was changed every 3 days initially followed by 7 days and finally 15 days eventually.

Histopathological examination of marsupialized tissue confirmed the diagnosis as the infected radicular cyst with a cystic lumen lined by stratified squamous epithelium showing an arcading pattern. OPG repeated at 3 months and 6 months revealed progressively decreasing radiolucent area of cystic space

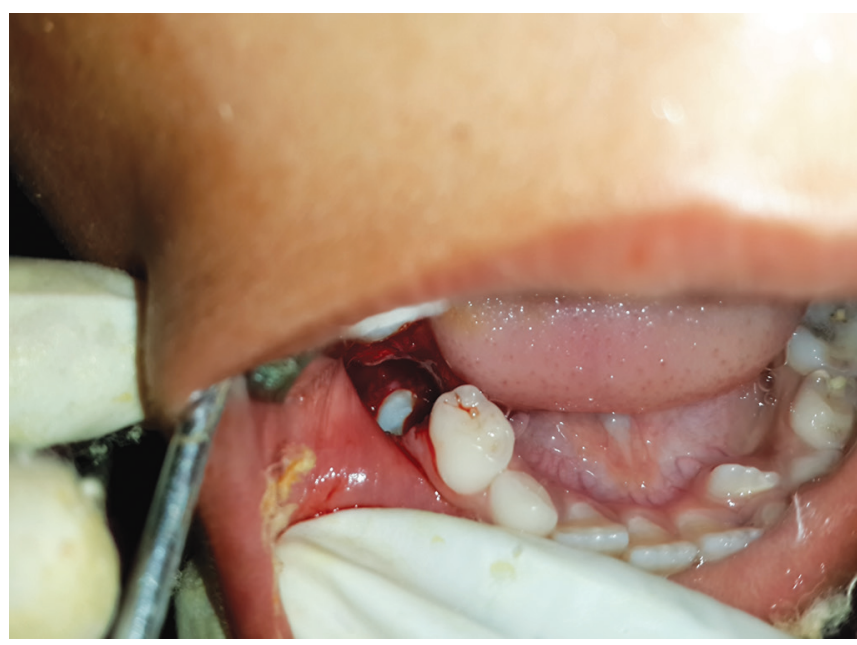

Fig. 3: Underlying cyst lining was gently eased away from the cavity

and evidence of new bone formation (Fig. 4). The extraoral swelling caused by expansion of buccal cortical plate also disappeared. Band and loop space maintainer was cemented on 46 to preserve the space for erupting 45 (Fig. 5). Uprighting and proper positioning of the mesially impacted 45 was also observed in follow-up radiographic examinations at 3 months and 6 months respectively (Fig. 6).

\section{Discussion}

An extensive array of cysts and neoplasms can ensue in the maxillofacial region, and their cataloging can be difficult. ${ }^{2}$ An odontogenic cyst of inflammatory origin anteceded by chronic periapical granuloma as well as stimulation of cell rests of Malassez found in periodontal membrane is called a radicular cyst. ${ }^{3}$ Simon identified two definite categories of radicular cysts, those consisting of cavities confined within epithelial lining (true cysts) and those with epithelial lined cavities open to root canals. ${ }^{1}$

Pathogenesis of these cysts have been described as consisting of three recognizable stages: stage of initiation, stage of formation, and stage of enlargement. ${ }^{5}$ In the first stage, epithelial cell rests of Malassez in periodontal ligament begin to propagate by inflammation due to the necrotic debris and bacterial antigens formed from the inanimate pulp. The second phase manifests as the cyst cavity being lined by propagating epithelium, finally followed by growth and enlargement. ${ }^{6}$

Literature about treatment choices and results are limited and ambiguous. ${ }^{7}$ Myriad of experts elect conservative therapy with endodontic techniques. Nevertheless, for extensive lesions, endodontic treatment alone is inefficient and should be combined with decompression, marsupialization, or even enucleation. ${ }^{8}$ In this respect, lower morbidity, and bony in-growth occurring as lesion decreases in size, culminating in more normal bony contour favors marsupialization procedure. Hence, it needs a lengthy duration of postoperative maintenance posing a concern for the patient. It is probable that decrease in intracystic pressure is a major concern during the healing. Albeit it is unknown what proportion of these cysts can be anticipated to heal with only marsupialization, it is a useful modality for management that can be considered when negotiating large cystic lesions. ${ }^{5}$

As per Neaverth, marsupialization comprises of deroofing of exterior wall of the cyst by surgical incision followed by 


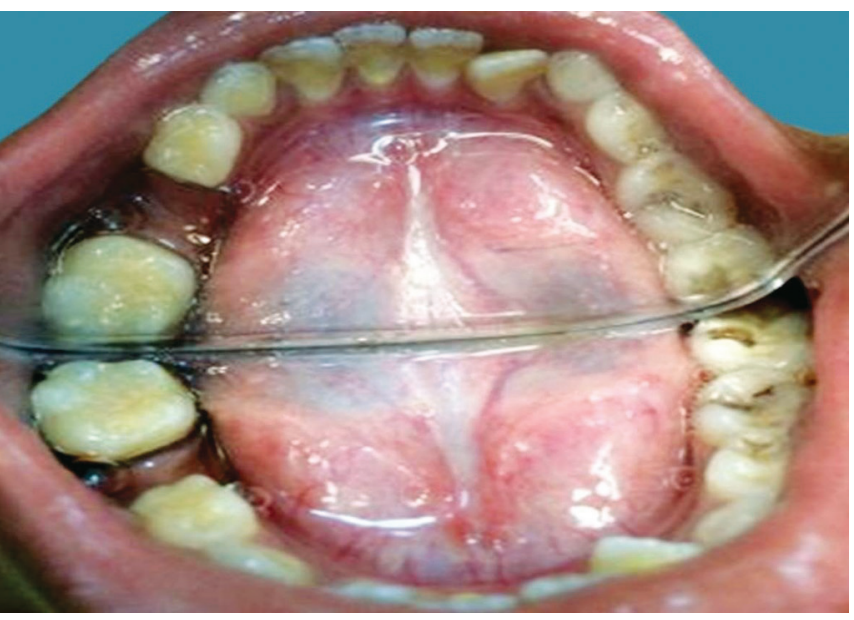

Fig. 5: Band and loop space maintainer placed in respect to 46

establishment of an enduring opening by suturing the left cystic wall to the surface of the mucosa. In the present case, marsupialization methodology exercised with extraction of correlated primary teeth to preserve permanent tooth buds appeared to be the most apt treatment option with normal alignment of permanent teeth that occurred impromptu. ${ }^{5}$

\section{CONCLUSION}

The treatment modality for radicular cyst generally includes enucleation if the cyst lining can easily be separated from its bone attachment and the cavity is filled with blood clot. As an alternative, large cysts can be marsupialized to relieve inside pressure. Considering the avoidable bone loss and that of vital teeth with enucleation, marsupialization is highlighted as more opportune in many aspects and is considered a valuable procedure for cases in which prominent radiolucent areas involve the developing tooth buds and antrum.

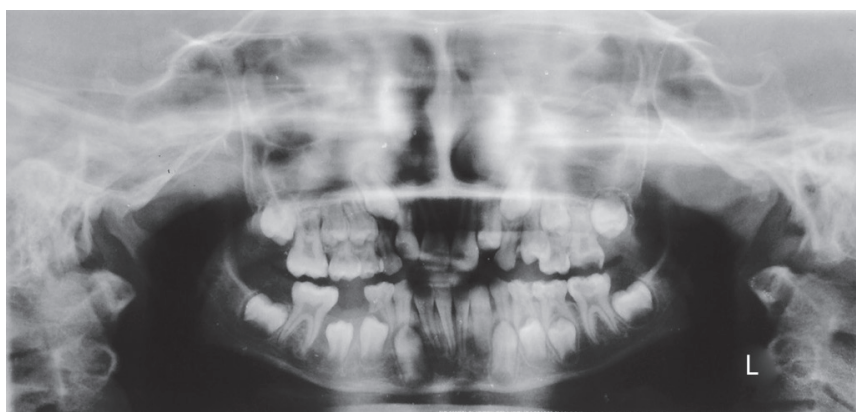

Fig. 6: Orthopantomogram reveals uprighting and proper positioning of the mesially impacted 45 in follow-up radiographic examinations at 6 months

\section{References}

1. Kumar JA, Achuthan N, Loganathan K, et al. Effective management of a large radicular cyst with surgical enucleation. Oral and Maxillofacial Pathol J 2014;5(1):459-461.

2. Ghezta N. Surgical enucleation of large radicular cyst-case report. J Dent Sci 2012;1(2):29-32.

3. Manwar NU, Agrawal A, Chandak MG. Management of infected radicular cyst by surgical approach. Int J Dent Clin 2011;3(4): 75-76.

4. Narula H, Ahuja B, Yeluri R, et al. Conservative non-surgical management of an infected radicular cyst. Contemp Clin Dent 2011;2(4):368-371. DOI: 10.4103/0976-237X.91806.

5. Harshitha KR, Varsha VK, Deepa C. Radicular cyst: a case report. Int J Appl Dent Sci 2015;1(4):20-22.

6. Kaur S, Gupta H, Singh H. Radicular cyst classic presentation: a case report and review of clinical, radiological and histopathological features. J Dent Med Sci 2017;16(4):103-106. DOI: 10.9790/0853160403102106

7. Riachi F, Tabarani C. Effective management of large radicular cysts using surgical enucleation vs Marsupialization two cases report. Int Arab J Dent 2010;1(1):44-51.

8. Agarwal P, Sharma S, Trehan M, et al. Management of infected radicular cyst by marsupialization. World J Dent 2013;4(3): 214-216. 